University of Nebraska - Lincoln

DigitalCommons@University of Nebraska - Lincoln

Public Health Resources

Public Health Resources

2011

Motivational interview improves treatment entry in homeless veterans

\author{
R. Morgan Wain \\ VA Palo Alto Health Care System \\ Paula L. Wilbourne \\ VA Palo Alto Health Care System \\ Keith W. Harris \\ VHA Office of Mental Health Services \\ Heather Pierson \\ VA Puget Sound Health Care System \\ Jasmine Teleki \\ Stanford Psychiatry and Behavioral Sciences \\ See next page for additional authors
}

Follow this and additional works at: https://digitalcommons.unl.edu/publichealthresources

Part of the Public Health Commons

Wain, R. Morgan; Wilbourne, Paula L.; Harris, Keith W.; Pierson, Heather; Teleki, Jasmine; Burling, Thomas A.; and Lovett, Steven, "Motivational interview improves treatment entry in homeless veterans" (2011). Public Health Resources. 199.

https://digitalcommons.unl.edu/publichealthresources/199

This Article is brought to you for free and open access by the Public Health Resources at DigitalCommons@University of Nebraska - Lincoln. It has been accepted for inclusion in Public Health Resources by an authorized administrator of DigitalCommons@University of Nebraska - Lincoln. 


\section{Authors}

R. Morgan Wain, Paula L. Wilbourne, Keith W. Harris, Heather Pierson, Jasmine Teleki, Thomas A. Burling, and Steven Lovett 


\title{
Motivational interview improves treatment entry in homeless veterans
}

\author{
R. Morgan Wain a , Paula L. Wilbourne ${ }^{b}$, Keith W. Harris ${ }^{c}, *$, Heather Pierson ${ }^{d}$, \\ Jasmine Teleki ${ }^{\mathrm{e}}$, Thomas A. Burling ${ }^{\mathrm{f}}$, Steven Lovett ${ }^{\mathrm{g}}$ \\ a VA Palo Alto Health Care System, 180D, 795 Willow Road, Menlo Park, CA 94025 USA \\ b Addiction Treatment Services, VA Palo Alto Health Care System, 180D, 795 Willow Road, Menlo Park, CA 94025 USA \\ ${ }^{\mathrm{c}}$ National Director of Clinical Operations, VHA Office of Mental Health Services, Homeless E Residential Rehabilitation Treatment Programs, 39199 Liberty Street, \\ Fremont, CA 94538 USA \\ d VA Puget Sound Health Care System, Domiciliary, 9600 Veterans Drive, Tacoma, WA 98493 USA \\ e Stanford Psychiatry and Behavioral Sciences, Behavioral Medicine Clinic, 401 Quarry Rd., Stanford, CA 94304 USA \\ f 2258 Calabazas Blvd., Santa Clara, CA 95051 USA \\ ${ }^{g}$ Chief, Psychology Service (116B), VA Palo Alto Health Care System, 3801 Miranda Ave., Palo Alto, CA 94304 USA
}

\section{A R T I C L E I N F O}

\section{Article history:}

Received 2 March 2010

Received in revised form 29 October 2010

Accepted 2 November 2010

Available online 8 December 2010

\section{Keywords:}

Motivational interview

Homeless veterans

Treatment retention

Wait-list attrition

\begin{abstract}
A B S T R A C T
Motivational Interviewing (MI) has successfully been used to facilitate entry and compliance in drug and alcohol treatment programs. Some questions have been raised as to the effectiveness of MI in severely distressed populations. This study aims to assess the effectiveness of MI in a population of homeless, unemployed, and substance dependent veterans who are being wait-listed for entry into a residential treatment program. Seventy-five veterans placed on a wait-list were randomized to receive a single MI or standard (Std) intake interview. Outcomes assessed were entry, and length of stay (LOS). Secondary outcomes assessed included program completion and rates of graduation. Readiness to change and selfefficacy were assessed before and after the interview. Significantly more participants entered the program in the MI group (95\%) than in the Std group (71\%). Although those in the MI group remained in the program longer, and had higher program completion and graduation rates, these differences were not statistically significant. No significant between-group or within-group differences were found in readiness or selfefficacy. This study demonstrates that a single, easily administered intervention can increase program entry. Also based on the study findings, further research into the question of whether MI can increase program retention, in a severely distressed population, is warranted.
\end{abstract}

Published by Elsevier Ireland Ltd.

\section{Introduction}

Motivational Interviewing (MI) is an empirically supported, brief intervention. It is a client centered, directive treatment that increases intrinsic motivation to change by eliciting and resolving ambivalence and by eliciting and reinforcing the client's statements about his or her reasons, desire, ability, need and commitment to change (Miller and Rollnick, 1991; Miller and Rollnick, 2002). The principles of MI emphasize the importance of supporting client self-efficacy for making the changes the client chooses to make. Motivational interventions, particularly those that include assessment feedback (motivational enhancement therapies (MET)), have been shown to be effective for both drug and alcohol related problems in several meta-analyses and reviews (Hettema et al., 2005; Burke et al., 2003; Vasilaki et al., 2006; Dunn et al., 2001; Britt et al., 2003; Miller and Wilbourne, 2002).

\footnotetext{
* Corresponding author. Tel.: +1 650493 5000x27119; fax: +1 6506172787.

E-mail address: Keith.Harris@va.gov (K.W. Harris).
}

Clinical trials indicate that MI improves engagement, retention and outcome when added to traditional substance use treatment. Randomized trials testing MET (1-3 sessions) added to standard substance abuse treatment have shown MET to prime treatment by increasing treatment initiation, retention, and outcomes. For example, a single session of MET led to improved treatment engagement and decreased substance use in adolescents (Aubrey, 1998). Individuals entering outpatient substance use treatment, given an intake session delivered in a motivational style (without assessment feedback of MET), exhibited better treatment engagement than did those who received the standard intake (Carroll et al., 2001). Residents in an alcohol treatment program, given a two session assessment and an MI style assessment feedback interview, participated more fully in treatment and showed reduced alcohol consumption at three months post-intervention (Brown and Miller, 1993). Individuals using heroin, who received a three session MET intervention, showed improved outpatient treatment retention when compared to similar patients who did not receive the motivational component (Secades-Villa et al., 2004). Veterans attending out- 
patient treatment for alcohol use disorders, who received an additional $2 \mathrm{~h}$ of assessment and a $1 \mathrm{~h}$ MET session, had better three-month outcomes than control subjects who received the same assessment with an attention placebo interview (Bien et al., 1993).

MI has been less frequently tested in the most severely dependent populations and in those with co-occurring mental health concerns. Debate has arisen in the literature regarding how useful brief interventions, specifically MI, are in such populations. Moyer et al. found in their meta-analysis of studies comparing brief interventions with control conditions, in non-treatment seeking samples (e.g., primary care settings), that effect sizes were larger if participants with more severe alcohol problems were excluded (Moyer et al., 2002). However, there is growing evidence for the effectiveness of MI in individuals who have severe substance use problems. Bien et al. demonstrated the efficacy of a $1 \mathrm{~h}$ session of $\mathrm{MI}$ in alcohol dependent VA outpatients who were drinking over 90 standard drinks per week. Those receiving the intervention demonstrated better outcomes on a composite variable consisting of total standard drinks, peak blood alcohol level and percent days abstinent (Bien et al., 1993). Also, in a study of pregnant women who were recruited from a medical setting, Handmaker et al. observed a larger effect of a $1 \mathrm{~h}$ session of MI in those who initially had higher blood alcohol levels, one indicator of severity (Handmaker et al., 1999). In those with co-occurring mental health concerns, a series of brief MET sessions led to improved substance use outcomes in individuals diagnosed with psychoses (Kavanagh et al., 2004). A two session MI intervention that included personalized feedback for patients diagnosed with psychoses led to mixed results, with the MI group having better substance use treatment outcomes in cocaine users but with the standard psychiatric interview having better outcomes in the marijuana users (Martino et al., 2006). In sum, the literature suggests that motivational interventions may be helpful in those with more severe substance use concerns and in those with co-occurring mental health concerns.

It is consistently demonstrated in the literature that more time in treatment correlates with better long-term outcome (Condelli and Hubbard, 1994; Greenfield et al., 2004; Harris et al., 2005; Simpson et al., 1999; Welte et al., 1981; Zarkin et al., 2002), and the first step is treatment engagement. Individuals most in need of intensive substance abuse treatment (e.g., homeless, substance dependent, unemployed, co-occurring mental health concerns) often experience the most difficulty accessing care (Romeo, 2005). These individuals frequently encounter logistical problems, such as lack of access to information, limited transportation options or difficulty accessing a telephone. Homeless individuals often have little to no social support system, having exhausted their families' patience and resources. There may be cultural and other social influences that are not supportive of individuals seeking help (Christian and Abrams, 2003). In addition, many residential programs have wait-lists, due to demand exceeding availability (Humphreys et al., 1988). In light of these numerous potential obstacles to accessing treatment and the importance of retention in treatment, interventions that increase engagement and retention in homeless individuals may be particularly important. A brief intervention that improves treatment engagement and length of stay (LOS) in a homeless population with complex challenges could be a valuable, cost-effective addition to treatment programs. This study focused on an MI interview that was delivered in one session. The intervention was conducted without assessment or assessment feedback, to reduce the barriers to implementation that multiple sessions, lengthy assessment or assessment feedback might pose when working with a transient population or when implementing into routine clinical care.

\subsection{Objectives and hypotheses}

This study investigated whether a single session of MI without feedback during the screening process could facilitate meeting waitlist requirements, increase program entry, and support program retention in a population of homeless veterans. The Ml intervention was hypothesized to increase program admission, LOS, completion and graduation, as compared to the standard (Std) condition. As MI was developed to increase readiness to change and self-efficacy, it was hypothesized that readiness and self-efficacy would change as a result of the interview.

\section{Methods}

\subsection{Setting}

The Homeless Veterans Rehabilitation Program (HVRP), of the VA Palo Alto Health Care System (VAPAHCS), is a 180 -day, residential, domiciliary care program for homeless veterans. Applicants to the program are homeless, substance dependent, and predominantly unemployed, disenfranchised, and with social and relational difficulties.

\subsection{Program eligibility}

When veterans apply to the program, they are screened by a social worker for program eligibility; the veteran must be capable of self-care, homeless or at risk of homelessness, free of significant medical, psychological or legal problems that would interfere with residential treatment, and willing and able to return to work Eligible veterans are placed on a wait-list and given a tentative admission date.

\subsection{Wait-list compliance requirements}

The wait-list can be challenging for this population. Wait-listed veterans may be required to obtain medical clearance or to resolve pending legal issues. During the wait-list period, potential participants are instructed to call in every day, Monday through Friday, to check bed availability, and to abstain from substance use for at least $72 \mathrm{~h}$ prior to entry. These all require some motivation and initiative on the part of the veteran.

\subsection{Reasons veterans can be removed from the wait-list}

Veterans can be removed from the wait-list if they neglect to call for five consecutive weekdays, or fail to obtain the necessary clearances; however, entry requirements are somewhat flexible, e.g., in the case of someone whose urine is positive but who has otherwise met entry requirements, the veteran may be admitted but stabilized before full program participation.

\subsection{Participants}

Participants were enrolled in the study from May 2004 through September 2005 The number of participants enrolled was determined by veteran and study personnel availability. Baseline and demographic characteristics are reported in Table 1.

\subsection{Procedure}

Wait-listed veterans were referred to study personnel on the day of their screening, if study interviewers were available that day. Potential study participants were assured that neither participation nor refusal would influence their eligibility for program entry. Seventy-five wait-listed veterans were assigned, by computergenerated randomization, to receive either a single session of MI $(n=41)$ or a Std interview $(n=34)$.

The HVRP screening interviewer and veteran were blind to whether the veteran would be assigned to the MI or Std group. Study interviewers were not blind to which group the veteran was assigned, as participants had to be matched with an MI or Std interviewer, based on the randomization sequence. Both groups were given the same series of questionnaires to test readiness and self-efficacy, followed by the study interviews. The Std and MI interviews were concluded with four questions to determine if the randomized groups were similar in terms of length of time unemployed, housing situation, drugs of choice and length of current abstinence. Readiness and self-efficacy questionnaires were repeated after the interviews. Interviews were audiotaped to allow subsequent review. After the study interviews, participants continued with the wait-list process. Participants' program entry, completion, graduation, and overall length of stay were tracked. Participants who were removed from the waitlist, or who chose not to enter the program, were no longer followed.

The Administrative Panel on Human Participants in Medical Research, Administrative Panels Office, Stanford University approved this study. 
Table 1

Demographics and baseline characteristics.

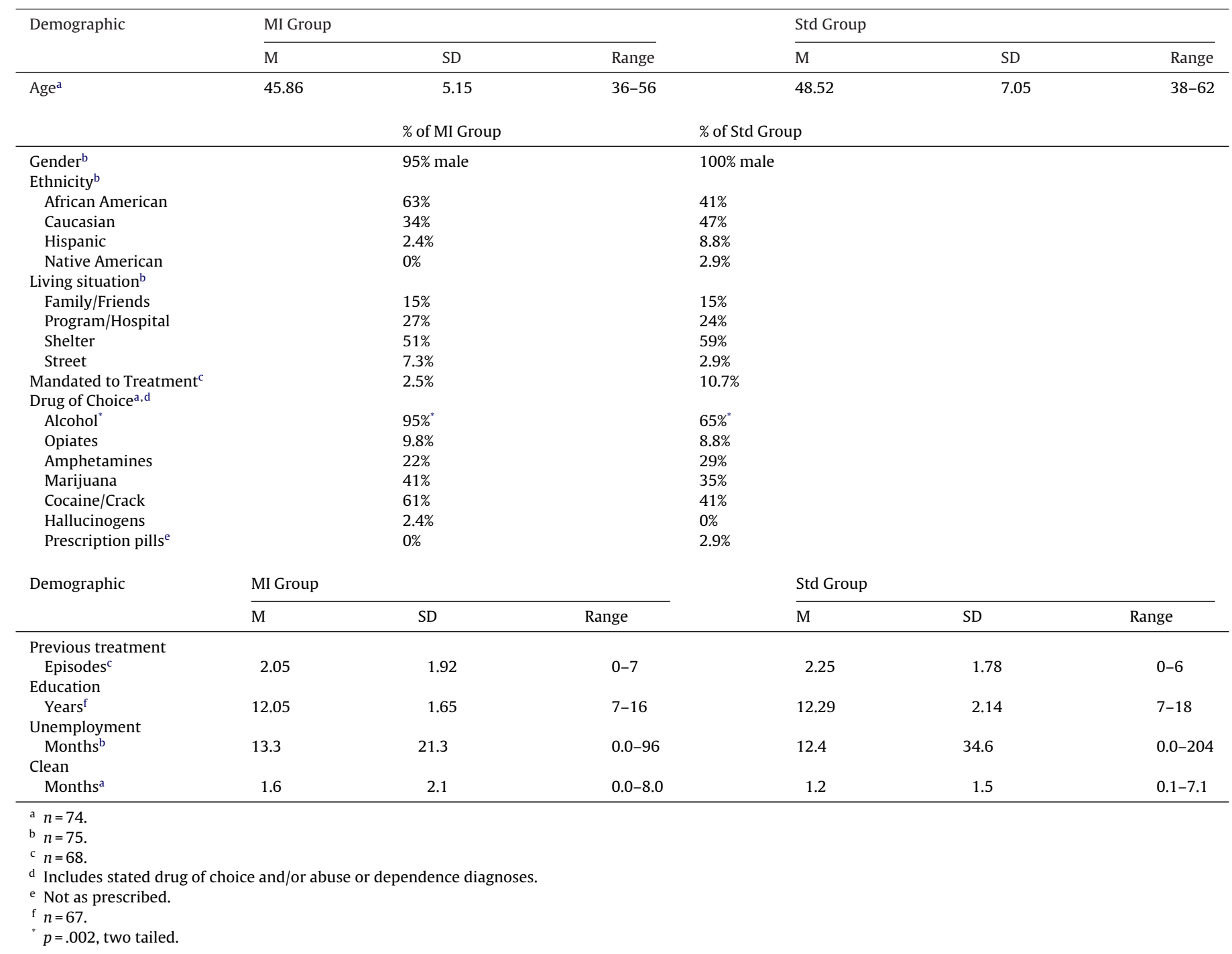

\subsection{Interventions}

The MI interviews were conducted according to a treatment manual developed for this project, based MI treatment principles outlined in the Project MATCH Motivational Enhancement Therapy treatment manual (Miller et al., 1992), while omitting the elements specifically focused on providing feedback. The MI intervention used in this study was designed to help the participants resolve ambivalence around entering the treatment program. The first part of the session focused on the pros and cons of substance use, ambivalence about substance use, how challenges had been overcome in the past, and the discrepancy between the consequences of past behavior and current goals. The second part of the interview focused on how program entry related to achieving the stated goals, obstacles that might prevent the participant from achieving those goals, and how those potential obstacles might be overcome. Personal strengths used to overcome hurdles in the past were elicited from the veterans, with a prompt about how they might apply those strengths to engage in treatment. Additionally, participants were queried about their aspirations for the future, including a discussion about what it would take to reach those dreams, with the goal of eliciting an explicit view of future capability and statements about change. Sessions concluded with readiness and confidence rulers, and inquiries into the importance the participant placed on entering treatment.

The Std interviews were conducted to control for the extra procedures that study participants went through, without the motivational component. The Std interviewers were instructed to conduct an intake interview, including, for example, what brought the person to treatment, symptoms, previous treatment, medical conditions, and personal and social history.

\subsection{Interviewer training, treatment integrity, and tape coding}

One MS level trainee and one PhD level training practitioner conducted the MI interviews. The PhD level practitioner was trained by the Motivational Interviewing
Network of Trainers (MINT), and had eight years of experience practicing MI. The trainee participated in a two-day workshop and received written feedback on three training and pilot tapes. Audio taped practice interviews were scored according to the Motivational Interviewing Treatment Integrity (MITI), Version 2.0, which defines scores for "beginning proficiency" and "competency" (Moyers et al., 2004). Once the trainee reached competency with MI, study participants were enrolled. Throughout the study, both MI interviewers participated in twice monthly supervision sessions focused on MI adherence, including review of audiotapes, to maintain competency (Miller et al., 2006; Miller et al., 2004).

The Std interviews were conducted by four graduate students who had completed a clinical interviewing course and were in their first year of supervised clinical practice. These interviewers were unfamiliar with MI, to prevent the inadvertent use of MI techniques (Miller et al., 2003).

All of the study interviews (MI and Std) were audio taped. Approximately midway through data collection, tapes of the two MI interviewers were compared on MITI scores, to assess interviewer integrity. Both interviewers scored at or above competency on all aspects, with the exception that the PhD interviewer scored between proficiency and competency on Percent Open Questions.

At the end of data collection, MI and Std interviews were compared as groups on MITI scores (Table 2). The Std interviewers met beginning proficiency on only the percent of statements that were MI adherent.

Ten minute randomly selected segments of the majority of the tapes (71/75) were coded to assess treatment integrity (four tapes not available due to problems with recording equipment). One postdoctoral fellow coded the 71 interview tapes; 23 of those tapes $(23 / 71=32 \%)$ were also coded by one of three graduate student coders to allow examination of inter-rater reliability. The postdoctoral fellow had previous experience using and training other coders on the MITI for research purposes. The other tape coders were trained, and reliability was established, on five coded training tapes. Coders received feedback from the supervisor and the coding 
Table 2

Mean scores of standard and motivational interviewers.

\begin{tabular}{|c|c|c|c|c|}
\hline Rating & Beginning proficiency & Competency & Standard interviewa & MI interview ${ }^{\mathrm{b}}$ \\
\hline Global rating & 5 & 6 & 4.47 & 5.96 \\
\hline Reflection to question ratio & 1 & 2 & 0.53 & 5.67 \\
\hline Percent open questions & $50 \%$ & $70 \%$ & $33 \%$ & $72 \%$ \\
\hline Percent complex reflections & $40 \%$ & $50 \%$ & $27 \%$ & $83 \%$ \\
\hline Percent MI adherent & $90 \%$ & $100 \%$ & $94 \% \mathrm{c}$ & $94 \% \mathrm{c}$ \\
\hline
\end{tabular}

a 34 tapes coded in the Std group.

b 37 tapes coded in the MI group.

c These statements occurred infrequently across samples (adherent $M=3.01$, range $0-21$; non-adherent $M=0.11$, range $0-1$ ).

team every two weeks. The clinician coordinating the coding received formal training by the authors who developed the MITI. The mean intra-class correlation for the 23 tapes was 0.90 with a range of $0.61-0.99$. According to Cicchetti, correlations of 0.6-0.74 are good and 0.75-1.00 are excellent (Cicchetti, 1994).

\subsection{Measures}

The primary outcome measures for this trial were (a) program entry, and (b) LOS. Secondary outcome measures included (a) program completion (approximately 180 day LOS, meeting all program objectives of being clean, sober, housed and employed), and (b) graduation (program completion plus an additional 13 weeks of aftercare in HVRP and attendance of two outside self-help meetings per week). Tertiary measures included assessments of readiness to change and self-efficacy.

2.9.1. ALCREADI measures. Readiness to change was measured using the Alternate Short Forms of the Alcohol Readiness to Change Scale (ALCREADI-A and -B) questionnaires (Carbonari et al., 1996). The ALCREADI-A and ALCREADI-B were administered before and after the interviews, respectively. The ALCREADI-A and -B are comparable 12-item brief versions of the 32-item University of Rhode Island Change Assessment Scale (URICA) (McConnaughy et al., 1983), designed to yield an overall readiness to change alcohol use score. The instructions for these forms were modified to ask that participants answer in terms of problems related to both drug and alcohol use. Items are rated from 1 (strongly disagree) to 5 (strongly agree). The measures are scored by adding the means of the contemplation, action and maintenance items, and subtracting the mean of the precontemplation items. Scores under 10 are considered to be precontemplation; 10.3-11.7 contemplation, and scores above 12 are considered to be "participation" scores, equivalent to preparation (DiClemente, personal communication).

2.9.2. Situational confidence questionnaire. The situational confidence questionnaire (SCQ), administered before and after the interview, served as the measure of self-efficacy (Annis and Graham, 1988). The SCQ was developed to assess the level of confidence to resist the urge to drink in a variety of situations. The instructions for these forms were modified in this study to assess confidence to resist using alcohol or other illicit drugs (Burling et al., 1989). The 39-item SCQ is based on Bandura's cognitive-behavioral self-efficacy theory and measures confidence on a scale of $0-100 \%$, yielding a mean confidence score. The SCQ was scored according to the Annis and Graham User's Guide (Annis and Graham, 1988).

\subsection{Analytic plan}

To assess between-group differences in dichotomous outcomes (program entry, completion and graduation), binary logistic regression was used. Program entry data were collected from 75 participants, giving us an adjusted power of .28 to detect the observed $\mathrm{OR}=2.97$. The MI intervention was hypothesized to increase LOS above that of the Std condition; to assess between-group differences we used a univariate General Linear Model (GLM). Sixty-three participants entered the program; covariate data were available for 57 of these participants, giving us an adjusted power of .37 to detect the observed partial $E t a^{2}=.049$. It was hypothesized that those in the MI condition would show greater increases in readiness and self-efficacy to change alcohol and other drug use than those in the Std condition. To assess between and within-group changes, we used GLM analyses and paired-samples $t$-tests, respectively. An alpha of .05 was used for all analyses.

\section{Results}

Of the three potential covariates examined, interview length, wait-list time, and number of substances used, significant betweengroup differences were found for interview length and number of substances used. ${ }^{1}$ Interview length was significantly greater in the

1 "Number of substances used" was the sum of a person's drug abuse and dependence diagnoses and his or her stated drug of choice. A substance was counted only
Table 3

Outcome summary.

\begin{tabular}{lll}
\hline Variable & MI group & Std group \\
\hline Program entry $^{*}$ & $95 \%(39 / 41)^{*}$ & $71 \%(24 / 34)^{*}$ \\
Length of stay (days) $^{\mathrm{a}}$ & $152 \pm 69.2$ & $112 \pm 79.5$ \\
Program completion $^{\mathrm{b}}$ & $56 \%(23 / 41)$ & $29 \%(10 / 34)$ \\
Program graduation $^{\mathrm{b}}$ & $29 \%(12 / 41)$ & $18 \%(6 / 34)$ \\
Change in mean readiness score $^{\mathrm{c}}$ & $-0.37 \pm 1.29$ & $-0.44 \pm 1.62$ \\
Change in mean self efficacy score $^{\mathrm{d}}$ & $38.5 \pm 75.51$ & $19.7 \pm 56.49$ \\
\hline
\end{tabular}

a $n=57$.
b $n=68$.
c $n=66$.
d $n=67$.
${ }^{*} p=.017$.

MI group, compared to the Std group, so this was controlled in the between-group analyses, $\mathrm{MI}$ group $\mathrm{M}=38.1 \mathrm{~min}, \mathrm{SD}=16.2$, and Std group $\mathrm{M}=27.2, \mathrm{SD}=16.1, F(1,68)=.000, p=.008$. The betweengroup difference in number of substances used was found to be accounted for solely by more alcohol use in the MI group, so alcohol use was also controlled in the between-group analyses, MI group $\mathrm{M}=.95$, equivalent to $95 \%$ positive, $\mathrm{SD}=.22$, and Std group $\mathrm{M}=.65$, equivalent to $65 \%$ positive, $\mathrm{SD}=.49, F=80.92, p=.002$. Waitlist times (number of days between screening visit and program entry) were available only for those who entered the program, as those who dropped from the wait-list $(n=12)$ often did so without notifying the program. Among those who entered the program, there was no significant between-group difference in wait-list times, $\mathrm{MI}$ group $\mathrm{M}=11.8$ days, $\mathrm{SD}=8.58$, and $\mathrm{Std}$ group $\mathrm{M}=14.7$ days, $\mathrm{SD}=13.98, F(1,62)=4.89, p=.305$. There were no significant between-group differences in demographic characteristics, length of time unemployed, housing situation, or length of current abstinence.

Interview length and alcohol use were used as covariates in all of the following between-group analyses. The number of participants in each analysis varied because subjects were dropped from the relevant analyses if any data were missing: (a) three participants declined to answer all the questions on the questionnaires, so they were dropped from the readiness and self-efficacy analyses; and (b) interview length was not available for seven participants so those subjects were dropped from all covariate analysis. This study is reported using the Consolidated Standards of Reporting Trials (CONSORT) guidelines ${ }^{2}$ (Moher et al., 2001; Davidson et al., 2003). Primary and secondary outcomes are summarized in Table 3.

once, e.g., if a person had diagnoses of alcohol dependence and cocaine abuse and stated that his or her drug of choice was cocaine, the score was 2 . On the other hand if a person had diagnoses of alcohol dependence and cocaine abuse and stated that his or her drug of choice was methamphetamine, then the score was 3. Betweengroup differences in "number of substances used" were accounted for solely by a greater amount of alcohol use in the MI group.

2 CONSORT flow chart available as supplementary material. 


\subsection{Primary outcome analyses: program entry rates and LOS}

The group that received the MI interview had a 95\% rate of entry (39/41), significantly higher than the $71 \%$ program entry rate $(24 / 34)$ observed in the Std group. $\chi^{2}(1,68)=5.66$, OR $=2.97$, $p=.017$.

The average LOS during the year prior to this study was 114 days. While those in the MI group stayed in the program longer $(M=152$ days, $S D=69.2)$ than those in the Std condition $(M=112$ days, $S D=79.5$ ), the between-group difference was not significant, $F(1,57)=2.75$, partial Eta ${ }^{2}=.049, p=.103$.

\subsection{Secondary outcome analyses: completion and graduation}

There was no significant between-group difference in completion rates, though more participants in the MI group completed 56\% $(23 / 41)$ compared to the Std group $29 \%(10 / 34), \chi^{2}(1,68)=3.33$, $\mathrm{OR}=1.72, p=.068$.

There was no significant between-group difference in graduation, though more participants in the MI group graduated $29 \%$ $(12 / 41)$ compared to the Std group $18 \%(6 / 34), \chi^{2}(1,68)=2.85$, $\mathrm{OR}=1.85, p=.091$.

\subsection{Tertiary outcome analyses: readiness and self-efficacy}

Subjects began in the Contemplation stage, MI group $n=40$, $\mathrm{M}=11.3, \mathrm{SD}=1.89$; Std group $n=33, \mathrm{M}=11.3, \mathrm{SD}=1.53$. No significant between-group difference was found in change of readiness scores, $\mathrm{MI}$ group $\mathrm{M}=-.37, \mathrm{SD}=1.29$; Std group $\mathrm{M}=-.44, \mathrm{SD}=1.62$, $F(1,66)=.25$, partial Eta $=.004, p=.622$. Both groups remained in Contemplation stage, and within group changes were not significant, MI group $n=40, M=-.40$, SD 1.29, $t=-1.96$ (39), $r=.30$, $p=.057$; Std group $n=33, \mathrm{M}=-.47, \mathrm{SD}=1.49, t=-1.83$ (32), $r=.31$, $p=.076$.

We assessed for between-group and within-group changes in self-efficacy. The SCQ yields a total mean score on a scale from 0 to 100 . There was no between-group difference in change of mean SCQ score pre-to post-interview, MI group $M=5.35, S D=9.72$; Std group $\mathrm{M}=2.72, \mathrm{SD}=7.81, F(1,65)=.10$, partial $E t a^{2}=.002, p=.751$. There was a significant within-group increase in mean SCQ score from pre-to post-interview in the MI group $n=39, M=5.24$, SD 9.62, $t=3.40(38), r=.48, p=.002$, but not in the Std group $n=33, \mathrm{M}=2.20$, $\mathrm{SD}=8.02, t=1.58(32), r=.27, p=.124$.

\section{Discussion}

This study investigated whether a single session of MI during the screening process would increase program entry and LOS, completion and graduation rates, readiness, and self-efficacy in a population of homeless veterans. The MI intervention significantly increased program entry. While there were increases in LOS, completion, graduation and self-efficacy in the MI group, the between-group differences were not significant. We did not detect any between or within-group changes in readiness following the intervention.

The entry rate of the MI group was significantly higher than that of the Std group. While we do not know what the rate of entry would have been for the veterans in this study without any intervention, in the prior year 55\% of those placed on the wait-list entered the program, suggesting that many veterans placed on the wait-list do not enter the program. During this study two veterans (5\%) in the MI group left or were removed from the wait-list, while 10 veterans (29\%) in the Std group left or were removed, suggesting that the MI intervention may have positively impacted the veterans' motivation to comply with wait-list requirements, to stay on the wait-list, and to enter the program. This is a novel finding that supports the effectiveness of a brief MI intervention in facilitating program entry in treatment-seeking, substance-dependent, homeless veterans. The simplicity of this intervention (a single session without feedback, delivered by a non-licensed provider) would make it possible for even short-staffed programs to easily introduce this into their screening and entry process.

LOS was of particular interest given that increased time in treatment has been correlated with improved outcomes, both in the literature and in this specific program. A potential concern could be that facilitating treatment entry would bring in more severely distressed people, who would have a more difficult time remaining in treatment, and ultimately lead to increased drop-out rates. This does not appear to be the case. While the between-group difference was not statistically significant, we observed more than a month longer program retention in the MI group, which is certainly clinically relevant in a six-month program. The LOS analyses had very low power to detect the small to medium effect; a larger sample size would provide more conclusive information on whether the MI intervention increases LOS in this population.

Completion and graduation rates are directly connected to LOS, as remaining in the program long enough to achieve certain milestones is part of what is required for completion and graduation. However, more than time alone is required to meet those milestones, and it is feasible that MI could enhance motivation to accomplish the requisite program goals. The low power to detect changes in LOS would affect power to detect changes in completion and graduation, so these should also be assessed with a larger sample size.

There were no significant differences in the readiness to change scores. Most of the participants were being screened on their own initiative (not court mandated), and had reached the Contemplation stage, as captured by their initial scores. Perhaps it was not possible for them to become "more ready" at this point. The 12-item ALCREADI-A and -B were designed to be quick readiness screens; the 32-item version is a more reliable measure of individual stages (Carbonari et al., 1996). While the short forms were probably sufficient to determine similarity between-groups at baseline, they were likely not sensitive enough to detect small changes in readiness, if they did occur. In addition, the MI interviews explored how entering treatment fit in with accomplishment of any stated goals. There has been a distinction made in the literature between readiness to change a behavior and readiness for treatment (DiClemente, 1999); it is possible that, had we assessed for readiness for treatment, we might have seen an effect.

Analysis of the SCQ scores revealed no significant betweengroup difference in change of total mean self-efficacy scores. While differences were not significant, the MI group showed greater increases than the Std group in the total mean SCQ scores. There also was a significant within-group change of SCQ scores in the MI group, and a large effect, indicating that it would be worth exploring the impact of the MI intervention on SCQ scores in a larger sample.

In conclusion, the positive effects on program entry warrant further exploration. This study suggests that a single, brief session of MI can be a very useful intervention for severely distressed, homeless, substance dependent veterans, and that it may prove useful with other severely distressed populations as well. Furthermore, a protocol that does not require conducting a formal assessment and providing feedback would be much simpler to apply in a clinical setting than more complex interventions.

\subsection{Study limitations and future directions}

The small sample size is a limitation. This study yielded a clear between-group entry rate difference. A larger sample size could help answer the questions of whether the insignificant increases in LOS, completion and graduation in the MI group are meaning- 
ful or not. This, in turn, could lead to further research into how to best support and follow-up the MI intervention so that increased program entry would translate into increased LOS and improved long-term outcomes.

There are some improvements that could be made to the Std group. Std interviews were shorter, on average, than MI interviews. To help address the discrepancy, we included interview length as a covariate in our between-group analyses of MI effects. As Std interviewers were chosen based on their having passed a graduate level Clinical Interviewing course, and they were instructed to conduct a standard intake interview, their tapes were not reviewed in supervision as the MI tapes were. In retrospect, providing comparable supervision would have added another layer of consistency between the MI and Std groups. In future studies it would be important to better control interview duration in both treatment groups and to provide comparable supervision to all practitioners.

Given how successful the MI intervention was in facilitating program entry in this population, it would be interesting to try a similar intervention at the first contact the veteran makes with the program. Prior to the in-person screening interview, veterans phone in to be given a brief phone screening and to be scheduled for the on-site visit. There is an even higher attrition rate at this point; perhaps an MI intervention over the phone could facilitate the veterans making it to their first appointment. Likewise, as completion and graduation from HVRP have been correlated with improved long term outcomes (Harris et al., 2005), it would be important to look at an MI intervention more directly aimed at increasing completion and graduation rates. While the trend in greater LOS, completion, and graduation in the MI group in this study may indicate that the pre-treatment intervention was useful toward all of those goals, an MI intervention later in the program aimed directly at one or all of these targets would be worth evaluating.

\section{Role of funding source}

Nothing declared.

\section{Contributors}

Author Wain designed the study, wrote the protocol, recruited study staff, performed the Motivational Interview (MI) intervention, summarized the results, wrote the first draft of the manuscript and incorporated revisions.

Author Wilbourne contributed to the study design, trained personnel to conduct the MI intervention and to code interview tapes, supervised the tape coding, performed the MI intervention, performed some of the statistical analyses and provided manuscript revisions.

Author Harris contributed to the study design, supervised the project, performed some of the statistical analyses, and provided a significant amount of the manuscript revisions.

Author Pierson coded all of the tapes, performed statistical analyses of the MI proficiency ratings, and provided manuscript revisions.

Author Teleki coded a significant number of the tapes.

Author Burling mentored the project, in the context of a residential homeless program for veterans, and provided periodic review of the process.

Author Lovett provided additional mentoring of the project, in regards to MI in clinical settings, and provided periodic review of the process.

\section{Conflict of interest}

No conflict declared.

\section{Acknowledgements}

The authors would like to thank Wendy Cheng for assistance with the statistical reporting.

\section{Appendix A. Supplementary data}

Supplementary data associated with this article can be found, in the online version, at doi:10.1016/j.drugalcdep.2010.11.006.

\section{References}

Annis, H.M., Graham, J.M., 1988. Situational Confidence Questionnaire (SCQ-39): User's guide. Addiction Research Foundation, Toronto.

Aubrey, L. L., 1998. Motivational interviewing with adolescents presenting for outpatient substance abuse treatment. Dissertation Abstracts International, DAI-B 59-03.

Bien, T.H., Miller, W.R., Boroughs, J.M., 1993. Motivational interviewing with alcoho outpatients. Behav. Cogn. Psychother. 21, 347-356.

Britt, E., Blampied, N.M., Hudson, S.M., 2003. Motivational interviewing: a review. Australian Psychologist 38, 193-201.

Brown, J.M., Miller, W.R., 1993. Impact of motivational interviewing on participation and outcome in residential alcoholism treatment. Psychol. Addict. Behav. 7, 211-218.

Burke, B.L., Arkowitz, H., Menchola, M., 2003. The efficacy of motivational interviewing: a meta-analysis of controlled clinical trials. J. Consult. Clin. Psychol. 71, 843-861.

Burling, T.A., Reilly, P.M., Moltzen, J.O., Ziff, D.C., 1989. Self-efficacy and relapse among inpatient drug and alcohol abusers: a predictor of outcome. J. Stud. Alcohol 50, 354-360.

Carbonari, J.P., DiClemente, C.C., Addy, R., Pollak, K., 1996. Alternate short forms of the Alcohol Readiness to Change Scale. In: Paper presented at the Fourth International Congress on Behavioral Medicine, Washington, D.C.

Carroll, K.M., Libby, B., Sheehan, J., Hyland, N., 2001. Motivational interviewing to enhance treatment initiation in substance abusers: an effectiveness study. Am. J. Addict. 10, 335-339.

Christian, J., Abrams, D., 2003. The effects of social identification, norms and attitudes on use of outreach services by homeless people. J. Community Appl. Soc. Psychol. $13,138-157$.

Cicchetti, D.V., 1994. Guidelines, criteria, and rules of thumb for evaluating normed and standardized assessment instruments in psychology. Psychol. Assess. 6 284-290.

Condelli, W.S., Hubbard, R.L., 1994. Relationship between time spent in treatment and client outcomes from therapeutic communities. J. Subst. Abuse Treat. 11, 25-33.

Davidson, K.W., Goldstein, M., Kaplan, R.M., Kaufmann, P.G., Knatterud, G.L., Orleans C.T., Spring, B., Trudeau, K.J., Whitlock, E., 2003. Evidence-based behavioral medicine: What is it and how do we achieve it? Ann. Behav. Med. 26, 161-171.

DiClemente, C.C., 1999. Motivation for change: Implications for substance abuse treatment. Psychol. Sci. 10, 209-213.

DiClemente, C. C., personal email communication, January 10, 2008.

Dunn, C., Deroo, L., Rivara, F.P., 2001. The use of brief interventions adapted from motivational interviewing across behavioral domains: a systematic review. Addiction 96, 1725-1742.

Greenfield, L., Burgdorf, K., Chen, X., Porowski, A., Roberts, T., Herrell, J., 2004 Effectiveness of long-term residential substance abuse treatment for women: findings from three national studies. Am. J. Drug Alcohol Abuse. 30, 537-550.

Handmaker, N.S., Miller, W.R., Manicke, M., 1999. Findings of a pilot study of motivational interviewing with pregnant drinkers. J. Stud. Alcohol 60, 285-287.

Harris, K.W., Wain, R.M., Schauder, B., Ferber, L., 2005. Survival analysis of posttreatment inpatients of a residential treatment program for homeless veterans. In: Paper presented at the American Group Psychotherapy Association Annual Meeting, New York, NY.

Hettema, J.E., Steele, J.M., Miller, W.R., 2005. Motivational interviewing. Ann. Rev. Clin. Psychol. 1, 91-111.

Humphreys, K., Huebsch, P.D., Moos, R.H., 1988. The Department of Veterans Affairs Substance Abuse Treatment System: Settings, Services, Staffing, and Management Policies. In: Program Evaluation and Resource Center and VA Palo Alto Health Care System HSR\&D Center for Health Care Evaluation, Palo Alto, CA.

Kavanagh, D.J., Young, R., White, A., Saunders, J.B., Wallis, J., Shockley, N., Jenner, U., Clair, A., 2004. A brief motivational intervention for substance misuse in recent-onset psychosis. Drug Alcohol Rev. 23, 151-155.

Martino, S., Carroll, K.M., Nich, C., Rounsaville, B.J., 2006. A randomized controlled pilot study of motivational interviewing for patients with psychotic and drug use disorders. Addiction 101, 1479-1492.

McConnaughy, E.A., Prochaska, J.O., Velicer, W.F., 1983. Stages of change in psychotherapy: measurement and sample profiles. Psychother. Theor. Res. Pract. 20, 368-375.

Miller, W.R., Rollnick, S., 1991. Motivational Interviewing: Preparing People to Change Addictive Behavior. Guilford Press, New York, NY.

Miller, W.R., Rollnick, S., 2002. Motivational Interviewing: Preparing People for Change. Guilford Press, New York, NY. 
Miller, W.R., Wilbourne, P.L., 2002. Mesa Grande: a methodological analysis of clinical trials of treatments for alcohol use disorders. Addiction 97, 265-277.

Miller, W.R., Zweben, A., DiClemente, C.C., Rychtarik, R.G., 1992. Motivational Enhancement Therapy Manual. Project MATCH Monograph Series, Vol. 2. NIH Publication No. 94-3723. National Institute on Alcohol Abuse and Alcoholism, Rockville, MD.

Miller, W.R., Yahne, C.E., Tonigan, J.S., 2003. Motivational interviewing in drug abuse services: a randomized trial. J. Consult. Clin. Psychol. 71, 754-763.

Miller, W.R., Yahne, C.E., Moyers, T.B., Martinez, J., Pirritano, M., 2004. A randomized trial of methods to help clinicians learn motivational interviewing. J. Consult. Clin. Psychol. 72, 1050-1062.

Miller, W.R., Sorenson, J.L., Selzer, J.A., Brigham, G.S., 2006. Disseminating evidencebased practices in substance abuse treatment: a review with suggestions. J. Subst. Abuse Treat. 31, 25-39.

Moher, D., Schulz, K.F., Altman, D., 2001. The CONSORT statement: revised recommendations for improving the quality of reports of parallel-group randomized trials. JAMA 285, 1987-1991.

Moyer, A., Finney, J.W., Swearingen, C.E., Vergun, P., 2002. Brief interventions for alcohol problems: a meta-analytic review of controlled investigations in treatment-seeking and non-treatment-seeking populations. Addiction 97, 279-292.
Moyers, T.B., Martin, T., Manuel, J.K., Miller, W.R., 2004. The Motivational Interviewing Treatment Integrity MITI Code: Version 2.0. Unpublished manuscript, University of New Mexico, Center on Alcoholism, Substance Abuse and Addictions CASAA, Albuquerque, NM.

Romeo, J.H., 2005. Down and out in New York City: a participant-observation study of the poor and marginalized. J. Cult. Divers 12, 152-160.

Secades-Villa, R., Fernánde-Hermida, J.R., Arnáez-Montaraz, C., 2004. Motivational interviewing and treatment retention among drug user patients: a pilot study. Subst. Use Misuse 39, 1369-1378.

Simpson, D.D., Joe, G.W., Fletcher, B.W., Hubbard, R.L., Anglin, M.D., 1999. A national evaluation of treatment outcomes for cocaine dependence. Arch. Gen. Psychiatry 56, 507-514.

Vasilaki, E.I., Hosier, S.G., Cox, W.M., 2006. The efficacy of Motivational Interviewing as a brief intervention for excessive drinking: a meta-analytic review. Alcohol Alcohol. 41, 328-335.

Welte, J., Hynes, G., Sokolow, L., 1981. Effect of length of stay in inpatient alcoholism treatment on outcome. J. Stud. Alcohol 42, 483-499.

Zarkin, G.A., Dunlap, L.J., Bray, J.W., Wechsberg, W.M., 2002. The effect of treatment completion and length of stay on employment and crime in outpatient drug-free treatment. J. Subst. Abuse Treat. 23, 261-271. 